\title{
DISTRIBUIÇÃO ESPACIAL DOS FRAGMENTOS DE VEGETAÇÃO ARBÓREA DA REGIÃO METROPOLITANA DE CAMPINAS: UMA ANÁLISE COM USO DE FERRAMENTAS DE GEOPROCESSAMENTO
}

\author{
Daniel Henrique Candido${ }^{1}$, Lucí Hidalgo Nunes² \\ (recebido em 12.08.2009 e aceito para publicação em 23.03.2010) \\ RESUMO
}

O estudo avaliou a concentração e a distribuição espacial dos fragmentos de vegetação arbórea nos municípios pertencentes à região metropolitana de Campinas, no interior do estado de São Paulo. A análise foi feita mediante utilização de imagens coletadas pelo satélite brasileiro Cbers 2 , e seu posterior tratamento com uso de ferramentas de geoprocessamento, levando em consideração a presença de aglomerados de vegetais arbustivos que pudessem ser visualizados a olho nu na composição feita com as imagens desse satélite. É importante salientar que não foi feita nenhuma distinção entre espécimes nativos e exóticos. A situação de algumas cidades é preocupante no que tange à presença de vegetação, tendo em vista a pequena extensão das matas e praticamente ausência da mata ciliar, além de que em alguns casos os fragmentos estão distantes dos centros urbanos. Observou-se tendência espacial na rmc, pois as matas dos municípios situados no setor leste da região, que apresenta morfologia mais irregular, são mais preservadas.

Palavras-chave: Matas, Vegetação, Ambiente, Região Metropolitana de Campinas.

\footnotetext{
1 Geógrafo e Mestre em Geografia. Atualmente é doutorando do Instituto de Geociências da Universidade Estadual de Campinas (UNICAMP) - daniel.candido@ige.unicamp.br

2 Professora Doutora do Departamento de Geografia do Instituto de Geociências da Universidade Estadual de Campinas - luci@ige.unicamp.br
} 


\section{SPATIAL DISTRIBUTION OF FOREST FRAGMENTS IN THE METROPOLITAN REGION OF CAMPINAS, BRAZIL: AN ANALYSIS USING GEOPROCESSING TOOLS}

\section{ABSTRACT}

The study evaluated the concentration and spatial distribution of forest fragments in municipalities of the metropolitan region of Campinas, in the state of São Paulo, Brazil. The analysis was performed using images collected by the Brazilian satellite cbers 2 , subsequently treated by some geoprocessing tools, considering the existence of clusters of shrub and trees that could be easily visualized in the satellite composites. It is important to stress that any distinction was done between native and exotic species. There is concern over some cities due to the small size of forests and almost lack of the riparian vegetation. Moreover, in some cases the fragments are distant from the town center. It was observed a spatial trend within the metropolitan region, since the vegetation of the municipalities located on the eastern edge of the region, which presents irregular morphology, contains larger portions of forests preserved.

Key words: Forests, Vegetation, Environment, Metropolitan Region of Campinas. 


\section{INTRODUÇÃO}

A Região Metropolitana de Campinas (RMC) é uma área de elevada concentração industrial e populacional, composta por 19 municípios: Americana, Artur Nogueira, Campinas, Cosmópolis, Engenheiro Coelho, Holambra, Hortolândia, Indaiatuba, Itatiba, Jaguariúna, Monte Mor, Nova Odessa, Paulínia, Pedreira, Santa Bárbara d'Oeste, Santo Antônio de Posse, Sumaré, Valinhos e Vinhedo (Figura 1). Juntos, eles têm uma população aproximada de 2.650.000 habitantes (IBGE, 2010), sendo assim a nona maior região metropolitana do país. Classificando-se pelo Produto Interno Bruto, essa região responde por $9 \%$ do total de riquezas do Brasil (EMPLASA, 2010), ocupando a segunda posição entre as metrópoles do país.

Apesar de a maior parte dos municípios que formam a RMC ter origem relativamente antiga, o crescimento demográfico da região se tornou mais significativo após a década de 1970 (HOGAN, 2001), quando essas cidades se apoiaram na adoção de políticas desenvolvimentistas por parte do governo federal para equipar seus parques industriais. Ao mesmo tempo, diversas obras visando a melhoria da infraestrutura na área de transporte foram executadas, como a construção de amplas e modernas rodovias, que serviram como centros de captação de investimentos, atraindo ainda mais população ao local.

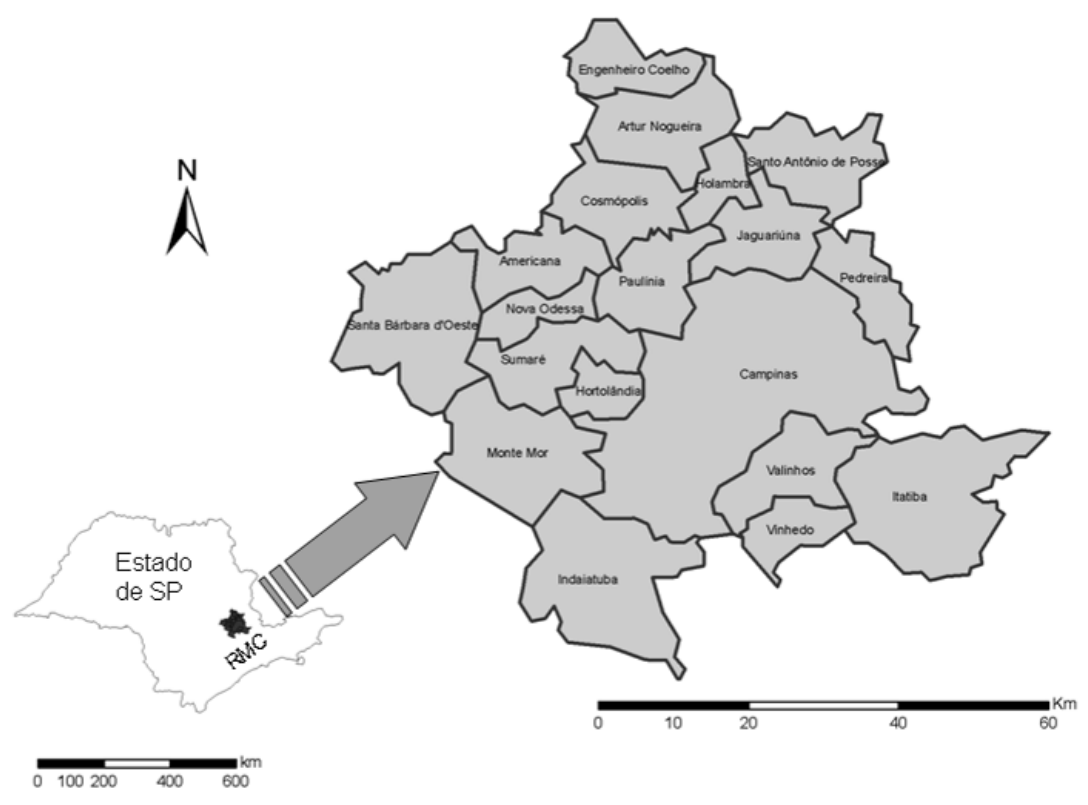

Figura 1: Localização dos municípios da Região Metropolitana de Campinas.

Com essa dinâmica, a expansão urbana tornou-se inevitável, acarretando efeitos colaterais, dentre os quais é possível destacar os danos ambientais (x) 
ocasionados pela sensível redução na quantidade de cobertura vegetal. Ao fenômeno da concentração populacional, soma-se a elevada demanda pelo uso das terras agricultáveis, sendo que certos municípios possuem raras áreas arborizadas, como Santa Bárbara d'Oeste, cidade que historicamente perdeu suas florestas para o cultivo da cana-de-açúcar, sendo que atualmente quase não existem áreas remanescentes de matas nativas (CANDIDO, 2007).

Esse aspecto exerce grande influência na qualidade de vida da população, uma vez que a presença de árvores exerce impacto significativo sobre o clima local. Dados apontam que a evapotranspiração é tão intensa, que apenas uma única árvore de grande porte seria capaz de proporcionar troca de calor na ordem de $2.500 \mathrm{kcal} / \mathrm{h}$, o que equivale a capacidade de resfriamento de cerca de dois aparelhos médios de ar condicionado (GREY e DENEKE, 1979; AGUIRRE JUNIOR e LIMA, 2007), auxiliando no abrandamento das chamadas ilhas de calor, estudada por autores como Lombardo, em seu clássico estudo para a cidade de São Paulo (1985). Pezzuto (2007) destaca que Campinas apresenta variações de até $7^{\circ} \mathrm{C}$ na temperatura, devido à elevada concentração urbana e industrial.

Tudo isso ressalta o importante papel da arborização, tanto em áreas urbanas como rurais. Além do efeito de arrefecimento térmico proveniente da evapotranspiração e modificação do albedo, as árvores apresentam outras características que podem auxiliar na qualidade de vida das cidades, podendo desempenhar papel fundamental na redução da ocorrência de certos hazards ambientais (WHITE, 1974; MATTEDI e BUTZKE, 2001; MARANDOLA JR e HOGAN, 2003; CANDIDO, 2007). Esse aspecto também foi destacado por Kobyiama e Silva (2003) em estudo que avalia o papel da vegetação ripária na prevenção de desastres naturais, ao diminuir a erosão e manter a morfologia da bacia, além de evitar ou diminuir a perda de solos férteis e o assoreamento dos canais.

Inundações também podem ser reduzidas sensivelmente com o aumento da população arbórea, uma vez que as folhas e galhos dos vegetais interceptam grande quantidade de água postergando, dessa forma, seu tempo de chegada aos dutos de drenagem. Os sistemas radiculares das árvores deixam as terras em seu entorno mais permeáveis, facilitando a infiltração, aumentando a recarga do freático e diminuindo o volume de água que compõe o escoamento superficial (CANDIDO, 2007).

As folhas e galhos das árvores atuam também como filtros, retendo parte do material particulado em suspensão no ar, sendo assim responsáveis por redução nos 
níveis de poluição atmosférica. As trocas gasosas ajudam a aumentar o teor de oxigênio disponível e contribuem, igualmente, na diminuição da quantidade de carbono na atmosfera, visto que durante seu crescimento esses vegetais capturam grandes quantidades desse elemento.

Além disso, as áreas mais arborizadas têm importante papel como centros de lazer para a população. Destaca-se que a Sociedade Brasileira de Arborização Urbana recomenda que os municípios mantenham uma área mínima de 15 metros quadrados de áreas verdes públicas para cada habitante do local (SBAU, 1996).

\section{MATERIAL E MÉTODOS}

Para a análise da distribuição espacial da vegetação arbórea na RMC, foram utilizadas imagens orbitais do satélite CBERS 2 coletadas em março de 2008 e disponibilizadas pelo Instituto Nacional de Pesquisas Espaciais (INPE). A composição escolhida foi RGB-432, por destacar a vegetação em vermelho escuro, permitindo distinção dos setores urbanizados, exibidos em tons de ciano. As áreas agrícolas podem ser diferenciadas da vegetação natural pela textura mais rugosa e bordas irregulares apresentadas pela última.

Em seguida, foi realizada uma classificação supervisionada com uso de um Sistema de Informações Geográficas (SIG), sendo que áreas contendo reservas de matas, bosques, parques e matas ciliares foram consideradas como amostras, necessárias para a posterior classificação executada pelo software ARCGIS 9.3.

Mesmo diversificando a escolha das amostras, o programa fazia certa confusão entre elementos distintos, classificando algumas áreas agrícolas e corpos d'água como vegetação arbórea. Tal fato estimulou a adoção da vetorização manual das áreas vegetadas, minimizando a ocorrência de erros. A classificação supervisionada, anteriormente produzida, foi utilizada como referência para eliminar dúvidas nessa etapa do processo.

Posteriormente, os dados foram analisados com uso do ARCGIS 9.3, obtendo informações quanto às áreas ocupadas e distribuição espacial dos elementos de interesse. Foi considerada vegetação arbórea qualquer aglomeração de árvores de grande porte visível na resolução disponibilizada pelo Satélite CBERS 2. Todas as feições capturadas na composição de imagens foram consideradas, independentemente de se tratar de vegetação natural ou plantada, uma vez que esse estudo compreende o mapeamento de árvores, em geral. Portanto, plantações de 
pinus e eucaliptos foram englobadas na mesma categoria que as árvores nativas existentes na área de estudo.

Apesar do CBERS 2 ter resolução espacial de 20 metros, árvores isoladas não puderam ser mapeadas, uma vez que somente são claramente distinguíveis as aglomerações de vegetais cujos dosséis sejam representados na imagem por valores superiores a cinco pixels, ou seja, aquelas formações englobem quadrículas com arestas superiores a 100 metros. Com isso, os menores fragmentos registrados nos mapas tinham cerca de 10.000 metros quadrados de área.

Salienta-se que todos os mapas exibidos neste trabalho apresentam suas coordenadas no sistema UTM, situadas dentro do fuso $23 \mathrm{~K}$, tendo sido elaborados utilizando o Datum SAD-69 (South American Datum, de 1969).

\section{RESULTADOS E DISCUSSÃO}

As composições elaboradas a partir das imagens orbitais mostram que os municípios localizados no setor leste da RMC apresentam maior quantidade de árvores em relação aos situados na porção oeste. A maior preservação das matas em tais locais provavelmente está relacionada à presença de relevo mais irregular, conforme pode ser constatado pela observação da Figura 2. Como relevos acidentados desfavorecem o uso agrícola intensivo das terras, existe uma tendência de maior ocupação das áreas mais planas, em detrimento das mais íngremes.

A Figura 3 mostra a distribuição dos aglomerados arbóreos observáveis nas imagens do satélite. Sua análise certifica o aspecto exibido na imagem anterior (Figura 2), mostrando que há maior concentração da vegetação na porção oriental da região metropolitana. É possível, ainda, notar grande fragmentação na distribuição dos remanescentes de florestas da região, sendo que o SIG apontou a existência de 1.375 frações matas não conectadas. 


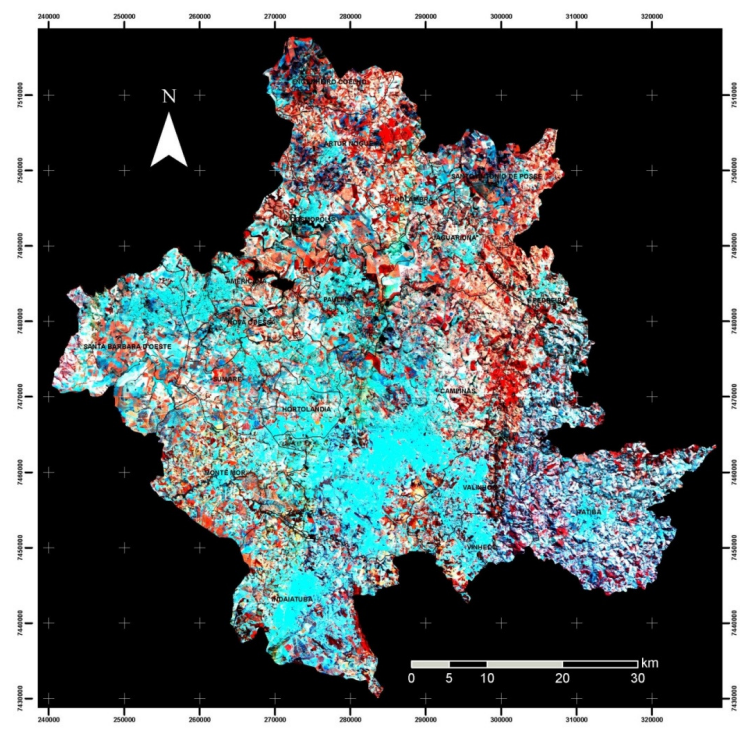

Figura 2: Composição de imagens do satélite CBERS 2 exibindo a Região Metropolitana de Campinas.

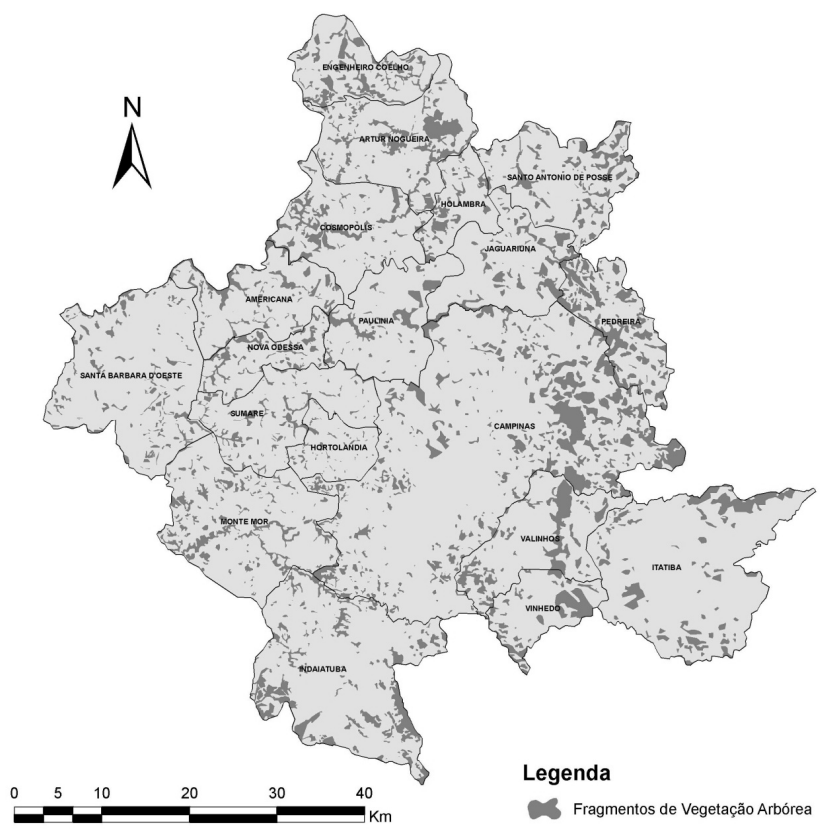

Figura 3: Distribuição espacial dos fragmentos de vegetação na RMC.

O maior desses fragmentos, medindo 1.460 hectares, encontra-se em área de relevo ondulado, no município de Valinhos. Contudo, essa medida pode estar superestimada, pois essa mata é dividida em quatro setores distintos, interligados por estreitas faixas de matas ciliares. Os municípios de Campinas, Itatiba, Artur Nogueira, Vinhedo, Indaiatuba, Engenheiro Coelho e Cosmópolis também apresentam fragmentos de vegetação de tamanhos significativos. O reconhecimento de suas 
dimensões é fator importante, pois matas maiores e com mais corredores de conexão têm maior capacidade de suporte à vida selvagem, uma vez que provêm mais segurança e alimentos aos animais (CÂMARA, 1996; ZAÚ, 1998; WWF, 2004). Devido ao elevado grau de fragmentação, é possível afirmar que poucas porções de matas da região têm tamanho suficiente para prover sustento aos animais de médio e grande porte que originalmente habitavam a área, como a jaguatirica, a suçuarana, o loboguará, entre outros.

A Tabela 1 permite observar a fragmentação da vegetação arbórea, em aglomerados, existentes na região. Confrontando essa informação com a área total de cada municipalidade, é possível perceber que nem sempre os maiores municípios apresentam as maiores quantidades de fragmentos. Essa tabela também permite perceber que o município com maior proporção entre território total e área ocupada por árvores é Pedreira, que contém $33,67 \%$ de suas terras cobertas por essa vegetação. Em seguida aparecem Vinhedo, com 24,18\% e Engenheiro Coelho, com 23,07\%. No lado oposto da tabela estão os municípios com menor presença de vegetação, sendo que Hortolândia e Santa Bárbara d'Oeste possuem, respectivamente, cobertura arbórea em apenas 5,93\% e 8,29\% de seus territórios.

Há de se considerar a grande extensão territorial ocupada por alguns municípios: Campinas, que apresenta fragmentos de florestas em área superior a 130 quilômetros quadrados, ocupa apenas a décima posição quando se considera o percentual de terras que contém alguma aglomeração de vegetação arbórea. Situação semelhante ocorre com Indaiatuba que, embora apresente quase 51 quilômetros quadrados de vegetação, está na nona posição quando considerada a proporção em relação à sua área. 
Tabela 1: Área total dos municípios da RMC e fragmentação da vegetação.

\begin{tabular}{|c|c|c|c|c|}
\hline \multirow[b]{2}{*}{ Municipalidade } & \multirow[b]{2}{*}{$\begin{array}{c}\text { Área total do } \\
\text { município }\left(\mathrm{km}^{2}\right)\end{array}$} & \multicolumn{3}{|c|}{ Fragmentação } \\
\hline & & $\begin{array}{l}\text { Número de } \\
\text { fragmentos }\end{array}$ & $\begin{array}{c}\text { Área } \\
\text { ocupada } \\
\text { (km2) }\end{array}$ & $\begin{array}{r}\text { Percentual } \\
\text { territorial }\end{array}$ \\
\hline Campinas & 796 & 315 & 130,26 & 16,36 \\
\hline Itatiba & 323 & 60 & 36,78 & 11,41 \\
\hline Indaiatuba & 311 & 102 & 50,94 & 16,40 \\
\hline Santa Bárbara d'Oeste & 271 & 99 & 22,53 & 8,29 \\
\hline Monte Mor & 241 & 103 & 31,24 & 12,96 \\
\hline Artur Nogueira & 178 & 68 & 34,67 & 19,49 \\
\hline Cosmópolis & 155 & 57 & 24,52 & 15,84 \\
\hline Santo Antônio de Posse & 154 & 67 & 27,66 & 17,94 \\
\hline Sumaré & 153 & 75 & 15,49 & 10,12 \\
\hline Valinhos & 149 & 35 & 29,84 & 20,09 \\
\hline Jaguariúna & 142 & 37 & 21,39 & 15,02 \\
\hline Paulínia & 139 & 34 & 15,86 & 11,39 \\
\hline Americana & 134 & 60 & 21,15 & 15,83 \\
\hline Pedreira & 110 & 61 & 36,98 & 33,67 \\
\hline Engenheiro Coelho & 110 & 40 & 25,36 & 23,07 \\
\hline Vinhedo & 82 & 26 & 19,78 & 24,18 \\
\hline Nova Odessa & 73 & 42 & 13,96 & 19,05 \\
\hline Holambra & 64 & 24 & 11,97 & 18,60 \\
\hline Hortolândia & 62 & 49 & 3,69 & 5,93 \\
\hline
\end{tabular}

\section{Situação de cada município}

Os mapas exibidos na sequência mostram a distribuição espacial detalhada da vegetação para cada um dos municípios da RMC, seguindo a ordem de percentual de terras cobertas por árvores, conforme dados fornecidos na Tabela 1.

Como já descrito, Pedreira é a cidade com maior presença de cobertura florestal, em proporção à extensão de seu território. A Figura 4 mostra que a vegetação está distribuída em grandes porções, espalhadas de forma homogênea. $A$ comparação entre esse mapa e a imagem CBERS utilizada como base mostra que as matas ciliares estão relativamente bem preservadas, sobretudo na área rural do 
município. No entanto, uma análise mais minuciosa mostrou que as zonas ripárias do Rio Jaguari carecem de vegetação, sobretudo no trecho em que esse canal fluvial cruza a área mais densamente urbanizada.

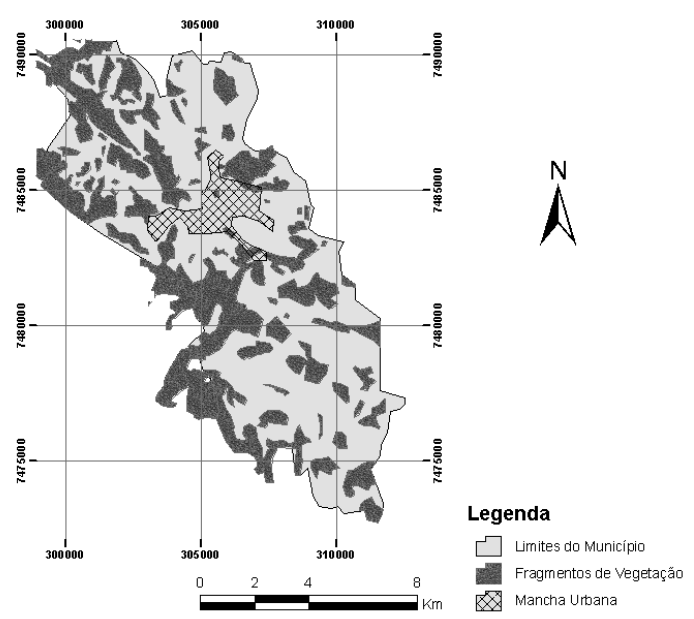

Figura 4: Distribuição espacial dos fragmentos de vegetação identificáveis nas imagens do satélite CBERS 2 para o município de Pedreira.

Vinhedo (Figura 5) já não apresenta tanta homogeneidade na distribuição da vegetação, mas a presença de uma área de mata relativamente grande em sua porção oeste faz com que ele seja o segundo município da RMC na proporção vegetação/território. Contudo, as imagens utilizadas indicam que o vigor da vegetação desse local é precária, o que fica evidenciado pela coloração menos intensa dos pixels correspondentes a essa formação. Além disso, merece menção o fato de existir grande pressão pelo uso da terra nesse local, devido à agricultura praticada em seu entorno, além da crescente demanda de áreas para execução de loteamentos e construção de condomínios (MIGLIORANZA, 2005). Harder et al. (2006) alertam que o índice de área verde total de Vinhedo está muito abaixo do mínimo de 15 metros quadrados por habitante, conforme sugerido pela Sociedade Brasileira de Arborização Urbana (SBAU, 1996), fato que pode ser observado pela pequena presença de fragmentos de vegetação dentro da mancha urbana do município, exibida na Figura 5. 


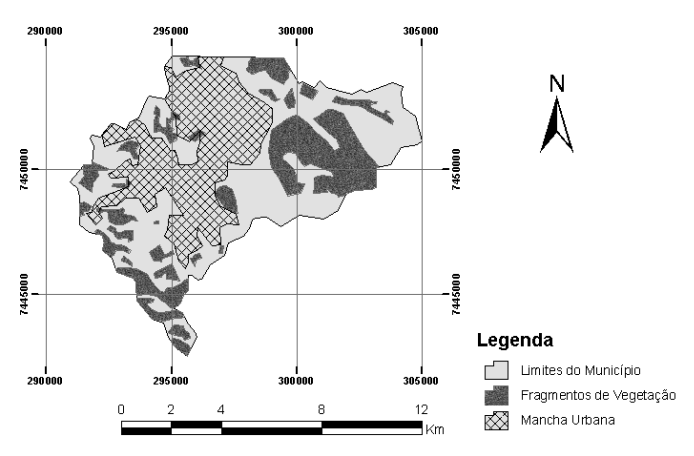

Figura 5: Distribuição espacial dos fragmentos de vegetação identificáveis nas imagens do satélite CBERS 2 para o município de Vinhedo.

O mapa exibido na Figura 6 mostra que o município de Engenheiro Coelho, situado ao norte da RMC, mostra distribuição homogênea da vegetação, com razoável conservação das matas ciliares. A análise da imagem de satélite mostra que mesmo nos locais onde a agricultura é praticada com maior intensidade, as terras situadas às margens dos canais fluviais são respeitadas, tendo sua vegetação preservada. No entanto, os valores totais de área ocupada por vegetação arbórea podem estar ligeiramente superestimados, uma vez que esse município apresenta grandes plantações de citrus, o que pode ter induzido a equívocos na classificação, tendo em vista que esta foi executada exclusivamente por meio de imagens orbitais.

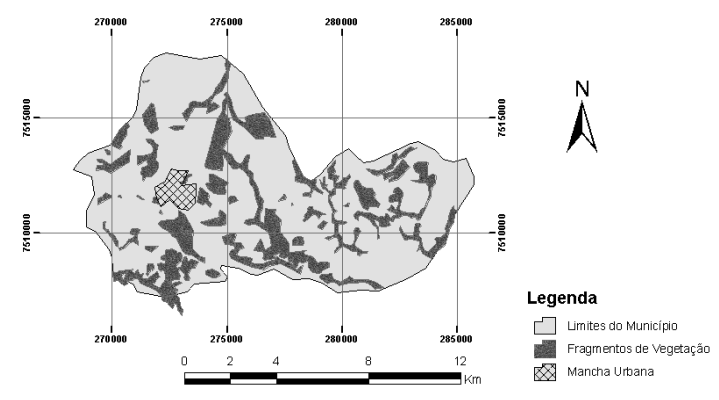

Figura 6: Distribuição espacial dos fragmentos de vegetação identificáveis nas imagens do satélite CBERS 2 para o município de Engenheiro Coelho.

Valinhos (Figura 7) exibe um grande corredor de vegetação cruzando o município no sentido norte-sul. Essa área está situada sobre uma formação de relevo mais elevado e irregular, conhecida como "Serra de Atibaia". Possivelmente a dificuldade de prática de agricultura nessa área teve papel fundamental na preservação de sua vegetação. O mapa também mostra a presença de alguns pontos 
de vegetação dentro da área urbana, que provavelmente correspondem à parques ou bosques mantidos no local.

Observa-se tendência de construção de grandes condomínios fechados nesse município, devido à proximidade geográfica com Campinas. Tais instalações procuram as áreas ocupadas por fragmentos de florestas, fazendo uso de estratégias de marketing ambiental para estimular a comercialização dos terrenos. As imagens de satélite mostram que muitos condomínios de Valinhos e da vizinha Vinhedo estão sendo construídos em locais com presença de volumosa vegetação, o que tem aumentado a pressão demográfica sobre esses locais.

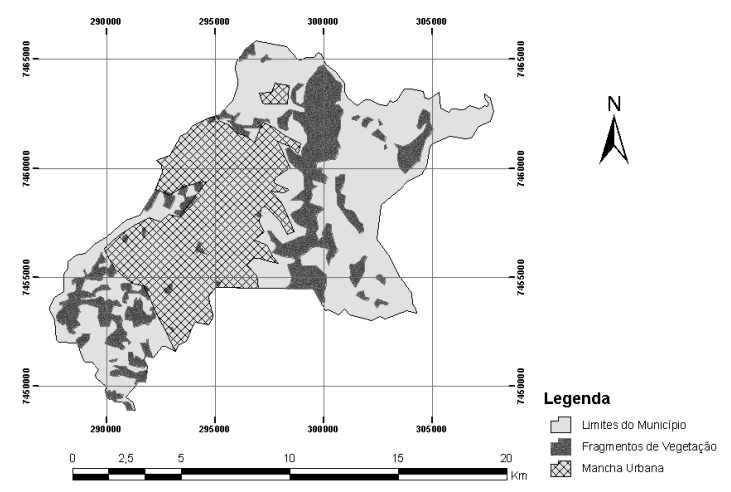

Figura 7: Distribuição espacial dos fragmentos de vegetação identificáveis nas imagens do satélite CBERS 2 para o município de Valinhos

Um estudo desenvolvido por Miglioranza (2005) tratando sobre o surgimento de condomínios fechados em Valinhos cita que "a urbanização desenfreada foi responsável por desmatamento e queimadas que logo deram lugar aos muros e condomínios, alguns sem áreas verdes e sem áreas coletoras de chuva". A baixa presença de fragmentos de vegetação dentro da mancha urbana do município, exibida na Figura 7, testemunha essa condição. 


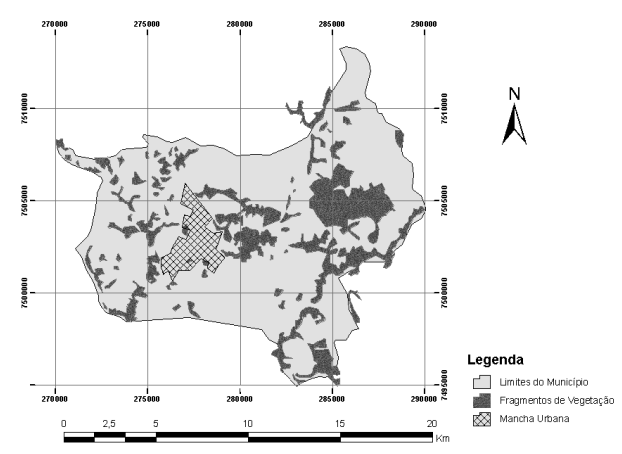

Figura 8: Distribuição espacial dos fragmentos de vegetação identificáveis nas imagens do satélite CBERS 2 para o município de Artur Nogueira.

Artur Nogueira (Figura 8) apresenta 19,49\% de seu território recoberto por vegetação arbórea. Esse município, tal como Engenheiro Coelho, apresenta densa citricultura, o que pode influenciar nos totais de áreas recobertas por árvores. As matas ciliares do setor oeste estão mais preservadas do que as situadas a leste, onde as imagens CBERS mostram que a agricultura é praticada até as margens de muitos dos córregos ali existentes. Nesse setor também se percebe grande fragmentação das matas, que se dividem em diversas partições menores, separadas por culturas agrícolas. Destaca-se a existência de um denso aglomerado de vegetação no setor oeste do município, atuando como ligação entre as matas ripárias de diferentes corpos hídricos.

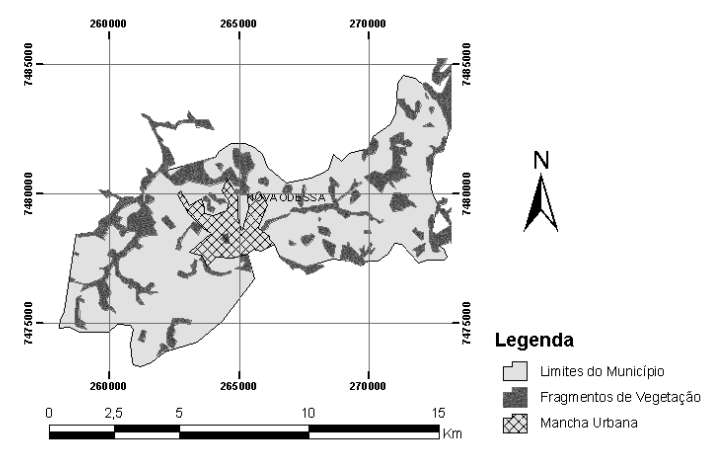

Figura 9: Distribuição espacial dos fragmentos de vegetação identificáveis nas imagens do satélite CBERS para o município de Nova Odessa.

No mapa que exibe a distribuição espacial da vegetação de Nova Odessa (Figura 9), percebe-se grandes extensões de matas distribuídas de forma longitudinal. Essas estruturas correspondem as zonas ripárias dos canais fluviais que cruzam 0 município nesse mesmo sentido. Merece menção o fato da imagem orbital utilizada 
como base para o mapeamento indicar que essa vegetação possui pouca massa foliar, o que ficou evidente pela menor reflectância na banda 4, que corresponde ao infra-vermelho próximo. Portanto, a vegetação está pouco vigorosa, carecendo de cuidados para sua manutenção.

O mapa e que exibe a situação de Holambra (Figura 10), traz a presença de grandes porções de matas em seu setor sudoeste, sendo que algumas destas chegam a transpor os limites municipais, compreendendo grandes áreas de vegetação compartilhada com municípios vizinhos. A mancha urbana é separada em duas, havendo um córrego com densa vegetação entre essas porções. Todavia, há pouca vegetação nas áreas onde a agricultura é mais intensa, sendo possível notar a existência de córregos com as margens totalmente desprovidas de vegetação.

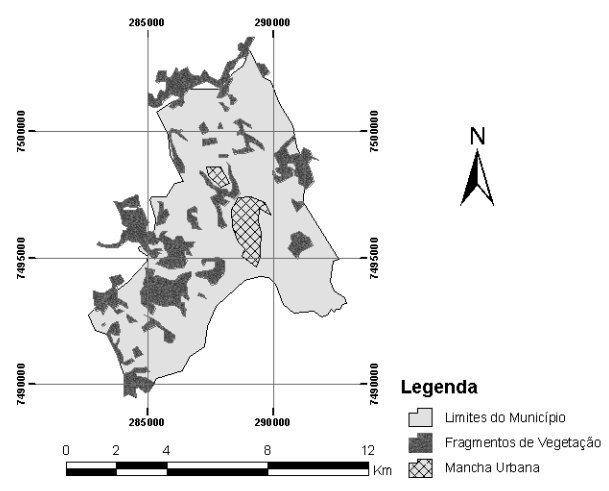

Figura 10: Distribuição espacial dos fragmentos de vegetação identificáveis nas imagens do satélite CBERS 2 para o município de Holambra.

O relevo irregular do município de Santo Antonio de Posse provavelmente contribui para que existam vários fragmentos de vegetação nesse local. A porção leste concentra a maior parte das árvores, contabilizando 46 fragmentos de áreas verdes (Figura 11). O relevo se aplaina no setor oeste, o que provoca diminuição na cobertura florestal, devido à maior prática de agricultura no local. Todavia, ainda é possível notar a presença de grandes corpos de vegetação ao longo de um riacho que nasce nessa parte do município. 


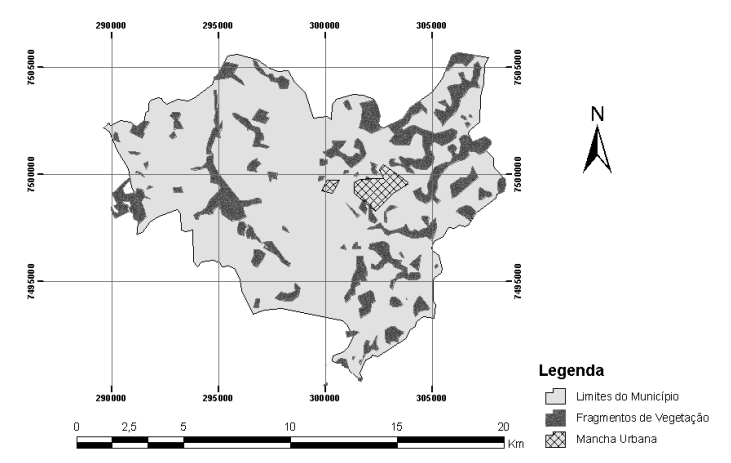

Figura 11: Distribuição espacial dos fragmentos de vegetação identificáveis nas imagens do satélite CBERS 2 para o município de Santo Antonio de Posse.

Em Indaiatuba (Figura 12) existem grandes porções de vegetação, mas a maior parte se situa próxima à linha divisória do município, estando assim afastadas do centro urbano. Há um fragmento particularmente grande no limite oriental, onde a imagem de satélite indica presença de vegetação densa e saudável, com tamanho suficientemente grande para prover suporte à vida selvagem (WWF, 2004).

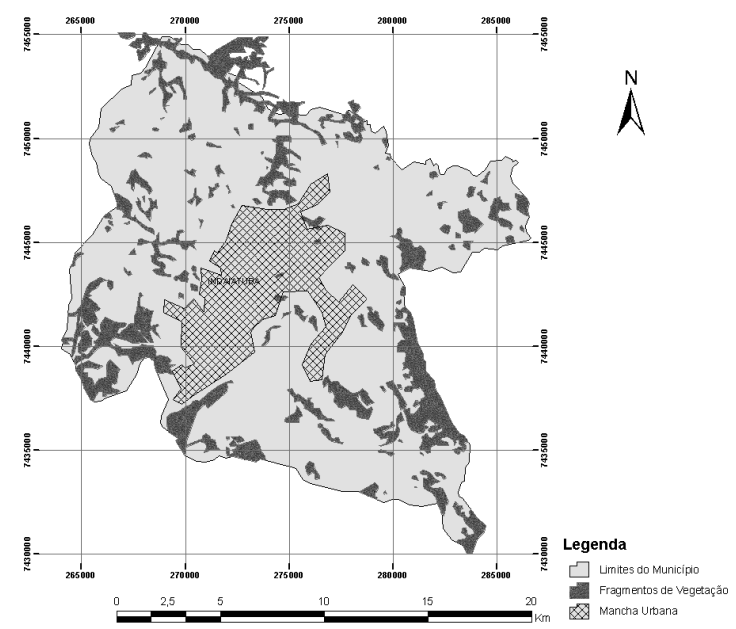

Figura 12: Distribuição espacial dos fragmentos de vegetação identificáveis nas imagens do satélite CBERS 2 para o município de Indaiatuba.

Além de ter a maior extensão territorial, o município de Campinas (Figura 13) apresenta, também, a maior área absoluta de vegetação. Entretanto, conforme relatado, sua extensão territorial faz com que ele ocupe a décima posição, considerando a proporção entre os tamanhos dos fragmentos de mata e a área total do município. 
A grande dimensão da mancha urbana faz com que a vegetação se encontre em porções bastante fragmentadas nas áreas mais densamente construídas. Com exceção de alguns parques mantidos em áreas urbanas, poucas formações são visíveis nesse setor. Porém, a leste do município há um setor de relevo acidentado e substrato mais rochoso, com baixa densidade de ocupação populacional. Conseqüentemente, é nesse setor que estão as maiores e mais bem preservadas matas.

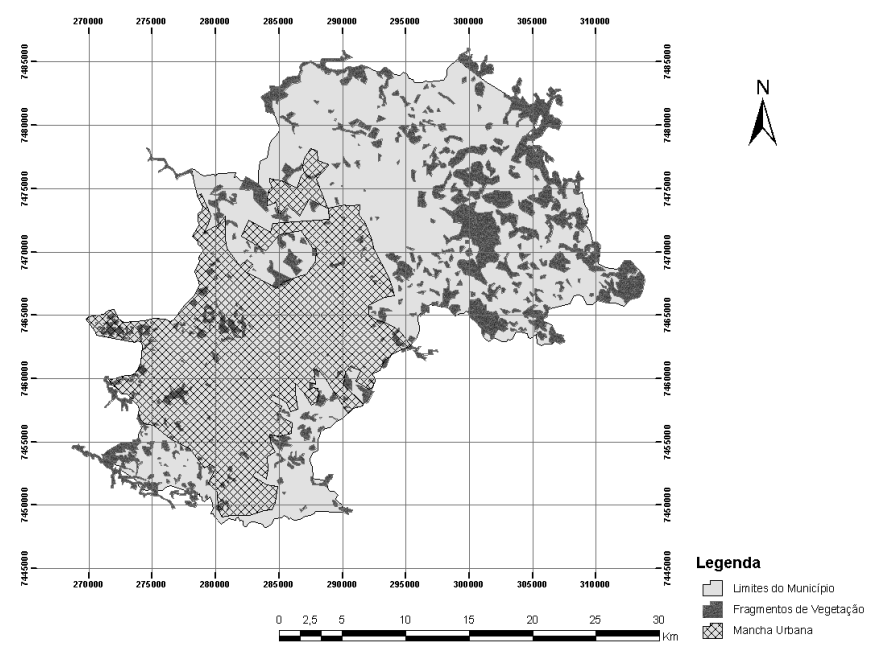

Figura 13: Distribuição espacial dos fragmentos de vegetação identificáveis nas imagens do satélite CBERS 2 para o município de Campinas.

Cosmópolis (Figura 14) e Americana (Figura 15) se encontram em estados similares, com poucos fragmentos de vegetação arbórea dentro de suas manchas urbanas. A situação é particularmente preocupante no entorno da represa de Salto Grande, que se situa na divisa entre esses dois municípios. A vegetação situada ao redor desse corpo d'água está sendo pressionada pela construção de chácaras recreativas e por práticas agrícolas inadequadas. As imagens de satélite permitiram ainda constatar que essa represa encontra-se em um elevado grau de eutrofização, com intensa presença de algas em suas águas. Nos dois municípios há pouca preservação das matas ciliares, sendo que as imagens utilizadas evidenciam a presença de canais fluviais totalmente desnudos de vegetação. 


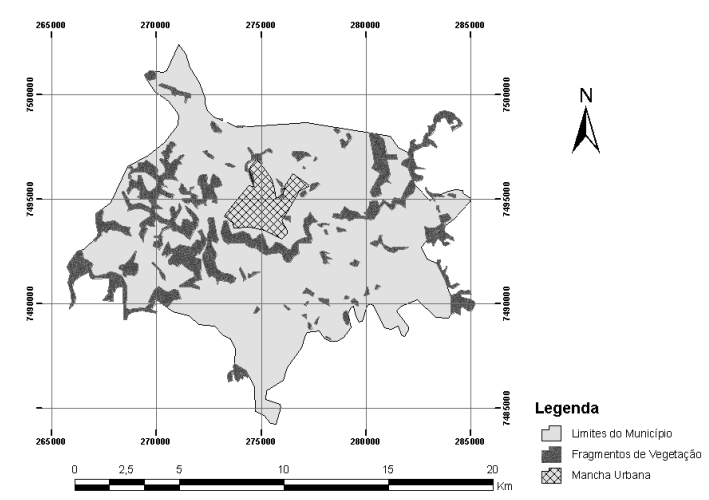

Figura 14: Distribuição espacial dos fragmentos de vegetação identificáveis nas imagens do satélite CBERS 2 para o município de Cosmópolis.

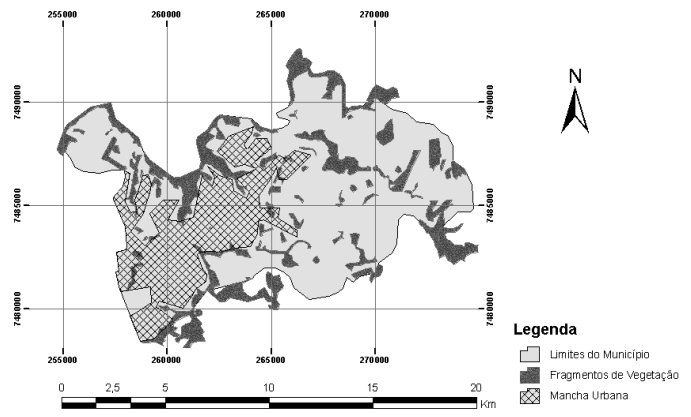

Figura 15: Distribuição espacial dos fragmentos de vegetação identificáveis nas imagens do satélite CBERS 2 para o município de Americana.

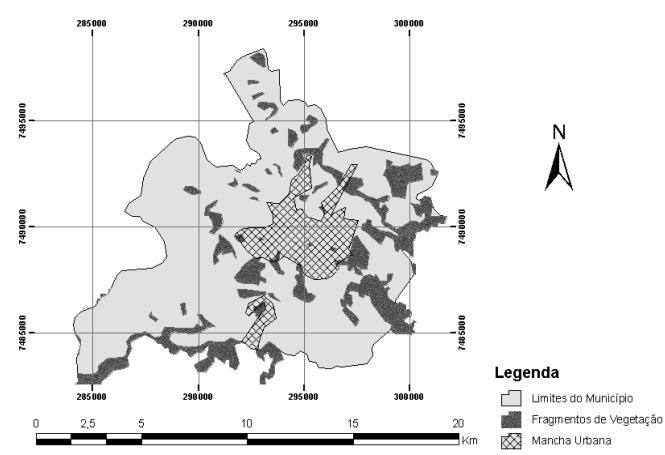

Figura 16: Distribuição espacial dos fragmentos de vegetação identificáveis nas imagens do satélite CBERS 2 para o município de Jaguariúna.

Apesar de apresentar proporção de ocupação por florestas abaixo da média da RMC, a Figura 16 mostra que Jaguariúna possui grandes fragmentos de vegetação, sobretudo nas linhas limítrofes com Campinas e Pedreira, de modo que as matas ciliares nesses locais estão relativamente bem desenvolvidas. É conveniente ressaltar 
que também é possível notar presença significativa de árvores nas proximidades da área mais densamente urbanizada.

O exame da Figura 17 evidencia que praticamente todas as matas do município de Monte Mor se concentram nas áreas ripárias, sendo que algumas cruzam a área urbana. No entanto, é possível ver alguns pontos onde a agricultura avançou até as margens dos canais, deixando-os totalmente desprovidos de proteção.

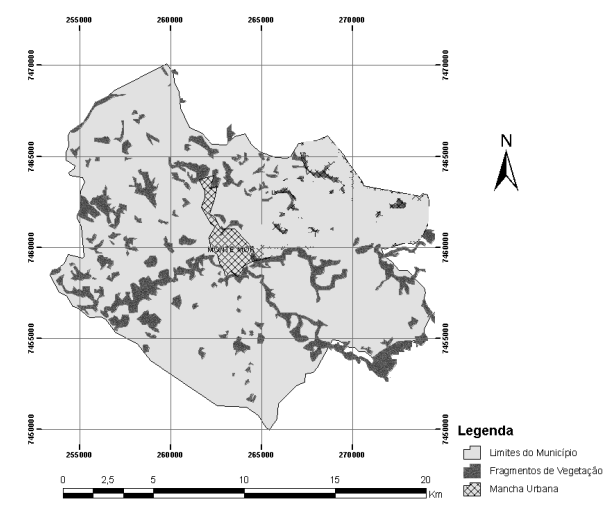

Figura 17: Distribuição espacial dos fragmentos de vegetação identificáveis nas imagens do satélite CBERS 2 para o município de Monte Mor.

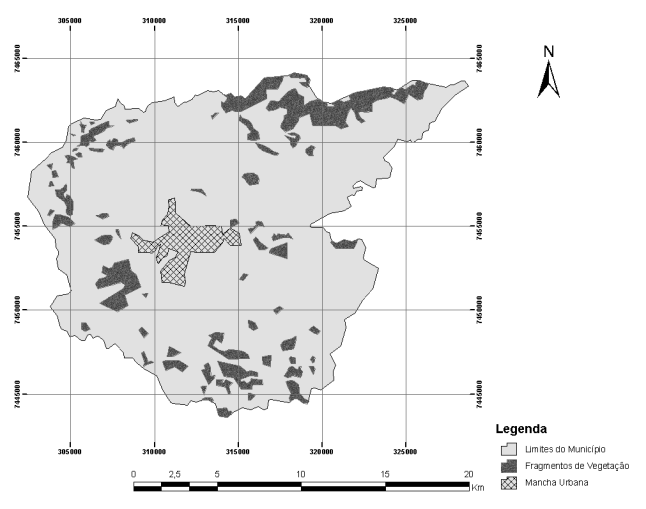

Figura 18: Distribuição espacial dos fragmentos de vegetação identificáveis nas imagens do satélite CBERS 2 para o município de Itatiba.

De modo geral, é possível afirmar que Itatiba apresenta poucos fragmentos florestais (Figura 18). Todavia, na parte mais colinosa de seu território, a noroeste, existe grande extensão de mata nativa, que se estrutura, sobretudo, nos topos dos morros ali existentes. No restante do município condomínios, fazendas e chácaras recreativas tomaram o espaço originalmente ocupado pelas florestas. 
A intensa industrialização da cidade de Paulínia (Figura 19) faz com que o município ocupe apenas a décima sexta posição dessa classificação, com 11,39\% de área recoberta (Tabela 1). A vegetação arbórea do município está praticamente restrita a uma faixa no sentido longitudinal, representando as matas que bordejam o Rio Atibaia. Dada à quantidade significativa de indústrias do ramo petroquímico instalada na cidade, é possível afirmar que os níveis de poluentes atmosféricos poderiam ser sensivelmente menores se existissem mais árvores no local.

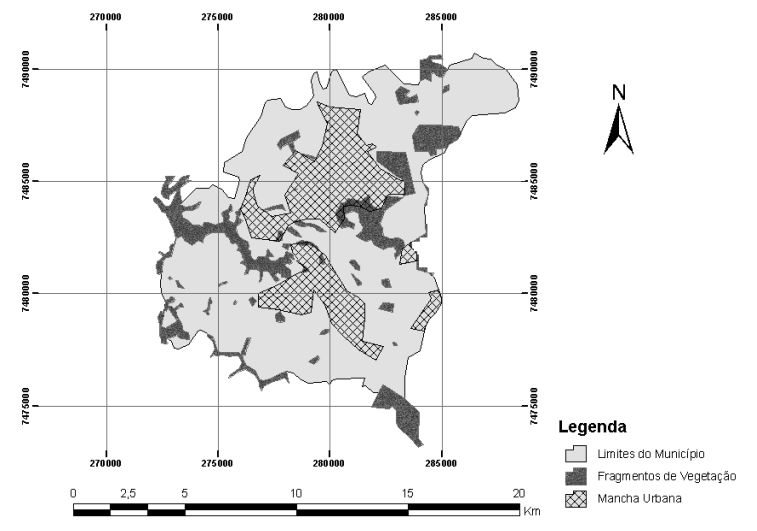

Figura 19: Distribuição espacial dos fragmentos de vegetação identificáveis nas imagens do satélite CBERS 2 para o município de Paulínia.

Outro município que apresenta intensa industrialização e pouca cobertura florestal é Sumaré (Figura 20), cujos dados mostram que os fragmentos de vegetação são pequenos e desconectados, o que não contribui na mitigação dos problemas ambientais relacionados à poluição desse local, e implica outros problemas, como a diminuição da umidade relativa do ar e a ausência de áreas verdes destinadas ao lazer da população. As imagens de satélite consideradas nessa análise também permitiram perceber que a massa foliar existente nas matas remanescentes desse município é relativamente pequena.

Considerando-se que esse é o segundo município mais populoso da região, o problema torna-se ainda mais significativo tendo em vista a presença de um grande parque industrial no local, cuja poluição poderia ser abrandada pela presença de vegetação mais substancial. 


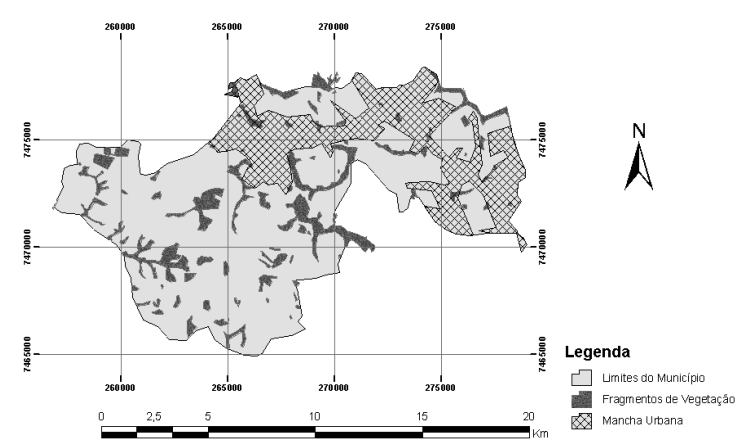

Figura 20: Distribuição espacial dos fragmentos de vegetação identificáveis nas imagens do satélite CBERS 2 para o município de Sumaré.

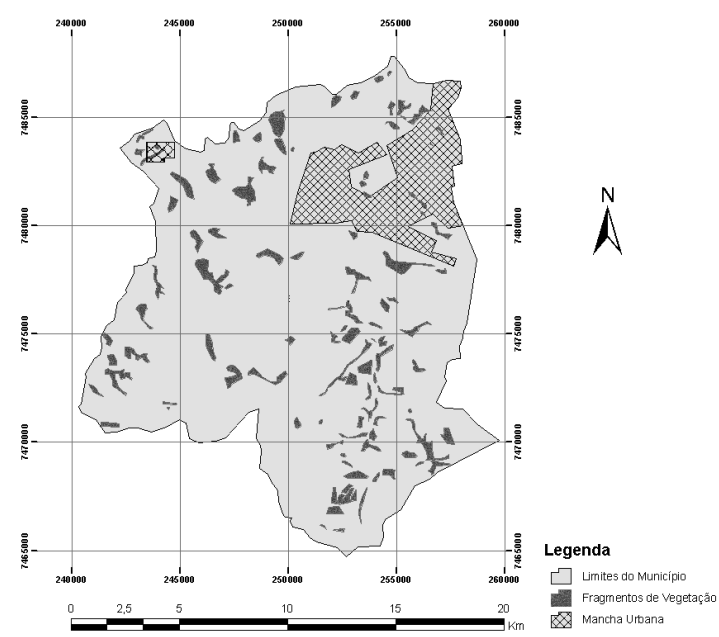

Figura 21: Distribuição espacial dos fragmentos de vegetação identificáveis nas imagens do satélite CBERS 2 para o município de Santa Bárbara d’Oeste.

Em situação ainda mais precária encontra-se o município de Santa Bárbara d'Oeste (Figura 21). Devido ao avanço do cultivo de cana-de-açúcar, a vegetação foi gradativamente sendo substituída pela agricultura, dando origem a uma ampla gama de problemas de ordem ambiental. Acrescenta-se, ainda, a quase ausência de fragmentos de vegetação na mancha urbana, o que intensifica os problemas decorrentes da poluição originada pelas indústrias locais e pelas queimadas praticadas nos canaviais, especialmente em alguns períodos do ano, que coincidem com aqueles em que o teor de umidade do ar é naturalmente mais baixo, contribuindo para a piora da saúde da população. Quanto a esse aspecto, destaca-se que esse 
município é o maior produtor de cana-de-açúcar da RMC e um dos únicos onde a queima da cana-de-açúcar continua sendo permitida.

Hortolândia, exibida na Figura 22, é também tem poucos fragmentos de vegetação, com o agravante de ser um município composto quase que exclusivamente por área urbana, sendo que em poucos setores existem aglomerações de árvores. $\mathrm{O}$ mapa mostra que poucas áreas estão preservadas, havendo séria carência de vegetação ripária. Destaca-se ainda que as pequenas porções de vegetação remanescente estão em péssimo estado de conservação, sofrendo intensa pressão da urbanização que vêm ocorrendo em seu entorno.

A falta de vegetação arbórea nesse município, em conjunto com a elevada poluição atmosférica local, tem conseqüência direta na qualidade de vida da população local, que sofre com os graves problemas ambientais decorrentes da pequena quantidade de vegetação aliada aos problemas relacionados à presença de indústrias de grande porte.

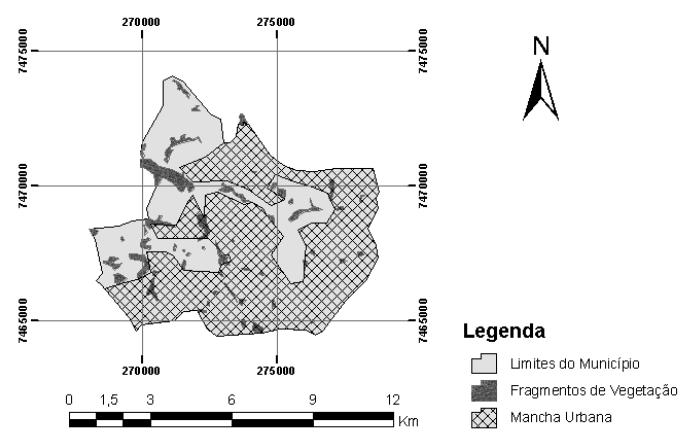

Figura 22: Distribuição espacial dos fragmentos de vegetação identificáveis nas imagens do satélite CBERS 2 para o município de Hortolândia.

\section{CONCLUSÕES}

Poucas áreas da Região Metropolitana de Campinas apresentam fragmentos de vegetação árbórea. Apesar de, na média, aglomerações de árvores recobrirem $15,7 \%$ de toda a área, essa distribuição é bastante desigual. De modo geral, o setor oriental da região é o mais beneficiado nesse aspecto, em virtude do relevo mais acidentado. As cidades da porção leste apresentam menos fragmentos de vegetação em função da elevada urbanização, induzida, dentre outros fatores, pela presença de importante modais (rodovias, ferrovias e aeroportos) e pelo relevo plano do local. 
Dada a intensa presença de indústrias potencialmente poluidoras, é imperativo que se empreguem esforços ingentes para a preservação da vegetação ainda existente em todos os municípios da região, seja ela nativa ou exótica.

Pedreira apresenta o maior percentual de vegetação arbórea. Ainda que não muito presente às margens dos rios que cruzam a área urbana, é possível afirmar que nesse município ela se encontra em bom estado de preservação quando comparada às demais cidades da RMC. Outros municípios que podem ser classificados em situação superior aos demais são Engenheiro Coelho, Vinhedo e Valinhos. Contudo, a situação dos dois últimos pode se alterar rapidamente em função da pressão imobiliária e também porque esses municípios integram o cinturão das frutas, onde produtos como figo, uva e morangos são cultivados, com alto consumo de água. Com isso é possível prever que os problemas atuais pela supressão de vegetação podem se agravar no futuro, dada a maior demanda hídrica devido ao tipo de agricultura praticada, que é também pouco inclusiva do ponto de vista social.

Sumaré, Santa Bárbara d'Oeste e Hortolândia encontram-se em situação crítica, devendo ser tomadas ações por parte dos poderes públicos municipais visando o plantio de árvores e manutenção das poucas áreas verdes existentes. Episódios recorrentes de inundações, como os estudados por Candido (2007) para Santa Bárbara d'Oeste atestam essa realidade. Nesse município, a grande pressão atual exercida pela cana-de-açúcar e as práticas pouco conservacionistas e permissivas, como a queima (prática abolida em tantos outros locais), contribui para a piora da qualidade de vida dos cidadãos, podendo onerar os cofres públicos devido à piora das condições de saúde (baixa umidade do ar e consequente problemas respiratórios, por exemplo). O direito ao lazer é também diminuído pela quase inexistência de parques públicos, o que também inibe a prática de exercícios e esportes, e convívio coletivo.

Merece igualmente destaque, o fato de não existirem aglomerações árbóreas dentro das áreas urbanas na maior parte dos municípios estudados. A implantação de bosques com plantio de vegetação nativa auxiliaria em muito a redução da poluição e minimização das variações de natureza climática (temperatura e umidade do ar, por exemplo), proporcionando maior qualidade de vida aos habitantes do local. Ademais, tais áreas poderiam se tornar em uma opção de lazer à população.

Por fim, sublinha-se que alguns municípios que apresentam economia mais robusta (como Campinas e Paulínia) demonstram pouco interesse preservacionista, com fragmentos pequenos de vegetação, alguns sob pressão urbana e afetados na 
integridade de suas estruturas arbóreas. Em médio e longo prazo isso compromete o bem estar das populações e promove problemas de ordens diversas, desde saúde pública até registro de inundações mais frequentes e catastróficas, dada a substituição da vegetação por materiais urbanos, que modificam o balanço hídrico e térmico dos locais.

\section{AGRADECIMENTOS}

Os autores gostariam de tornar público seus agradecimentos aos revisores da Revista da Sociedade Brasileira de Arborização Urbana pelos valiosos conselhos enviados após a revisão, que contribuiram com a melhoria desse artigo.

\section{BIBLIOGRAFIA}

AGUIRRE JUNIOR, J.H; LIMA, A.M.L.P. USO DE ÁRVORES E ARBUSTOS EM CIDADES BRASILEIRAS In: Revista Da Sociedade Brasileira de Arborização Urbana, Piracicaba, v.2, n.4, dez. 2007, p. 50-66.

CÂMARA, I.G. Plano de ação para a Mata Atlântica. Roteiro para a conservação de sua biodiversidade. Série Cadernos da Reserva da Biosfera, Caderno n4, São $\begin{array}{lllllll}\text { Paulo, } & 1996 . & 34 & \text { p.. } & \text { Disponível } & \text { em }\end{array}$ http://www.cprh.pe.gov.br/rbma/downloads/CadernosRB/n4.pdf > Acessado em junho de 2009

CANDIDO, D.H. Inundações no município de Santa Bárbara d'Oeste, SP: condicionantes e impactos. Dissertação (mestrado) - Instituto de Geociências, UNICAMP, Campinas, 2007. 235p.

GREY, G.W.; DENEKE, F.J. Urban Forestry. New York, John Wiley, 1978, 279p.

HARDER, I.C.F.; RIBEIRO, R.C.S; TAVARES, A.R. Índices de área verde e cobertura vegetal para as praças do município de Vinhedo, SP. Revista Árvore, Viçosa-MG, v.30, n.2, 2006, p. 277-282

HOGAN, D.J. (org.). Migração e ambiente nas aglomerações urbanas. Campinas: Núcleo de Estudos de População - UNICAMP, 2001. 515 p.

KOBIYAMA, M.; SILVA, R.V. da. Uso da zona ripária na prevenção de desastres naturais. Seminário de Hidrologia Florestal: zonas ripárias. I, Alfredo Wagner, SC, 2003. Anais... Alfredo Wagner, 2003, p.102-111. Disponível em: < http://www.labhidro.ufsc.br/Eventos/I\%20SHF/ZONAS\%20RIPARIAS-versao\%20finalrevisao2.pdf >. Acessado em junho de 2009.

LOMBARDO, M.A. Ilha de calor nas metrópoles. São Paulo, Hucitec, 1985. 244p. 
MARANDOLA JR., E.; HOGAN, D.J. Riscos e perigos: o estudo geográfico dos natural hazards. ENCONTRO TRANSDISCIPLINAR SOBRE ESPAÇO E POPULAÇÃO. 1, 2003, Campinas. Anais... Campinas: NEPO/ABEP, 2003. 13p. [CD-ROM] MATTEDI, M.A; BUTZKE, I.C. A relação entre o social e o natural nas abordagens de hazards e de desastres. Ambiente \& Sociedade. n.9 p.93-114, 2001 MIGLIORANZA, E. Condomínios fechados: Localizações de pendularidade - um estudo de caso no município de Valinhos, SP Dissertação (mestrado) - Instituto de Filosofia e Ciências Humanas, UNICAMP, Campinas, 2005. 105p PEZZUTO, C.C. Avaliação do Ambiente Térmico nos Espaços Urbanos Abertos. Estudo de Caso em Campinas, SP. Dissertação (mestrado) - Faculdade de Engenharia Civil, Arquitetura e Urbanismo, UNICAMP, Campinas, 2007. 186 p.

SBAU - SOCIEDADE BRASILEIRA DE ARBORIZAÇÃO URBANA. "Carta a Londrina e Ibiporã". Boletim Informativo, v.3 , n.5, p.3, 1996.

WHITE, G.F. Natural hazards research: concepts, methods, and policy implications. In: WHITE, G.F. (ed.) Natural hazards: local, national, global. New York: Oxford University Press, . p.03-16. 1974.

WWF. Visão de Biodiversidade da Ecorregião Florestas do Alto Paraná: Bioma Mata Atlântica. WWF e Fundación Vida Silvestre Argentina, 2004. Disponível em: < http://www.rbma.org.br/anuario/mata_06_fap_sumario_pag02.asp >. Acessado em junho de 2009.

ZAÚ, A.S. Fragmentação da Mata Atlântica: aspectos teóricos. Floresta e ambiente, Rio de Janeiro, v.5, no1, p. 166-170. 1998.

Websites consultados

EMPLASA - Empresa Paulista de Planejamento Metropolitano <www.emplasa.sp.gov.br> acesso em janeiro de 2010.

IBGE - Instituto brasileiro de Geografia e Estatística - <www.ibge.gov.br> acesso em janeiro de 2010.

INPE - Instituto Nacional de Pesquisas Espaciais - <www.inpe.br $>$ acesso em janeiro de 2010. 